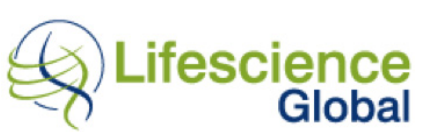

\title{
Effect of Sodium Hydroxide on the Fast Synthesis of Superhydro- phobic Powder from Polymethylhydrosiloxane
}

\author{
Saravanan Nagappan and Chang-Sik $\mathrm{Ha}^{*}$
}

Department of Polymer Science and Engineering, Pusan National University, Busan 609-735, Korea

\begin{abstract}
The paper reports the role of sodium hydroxide in the synthesis of a superhydrophobic powder from polymethylhydrosiloxane (PMHS) in the presence of ethanol and water. The effects of other basic and acidic solutions as well as the absence of water were also investigated. PMHS exhibited rapid gelation (from $8 \mathrm{~h}$ to $2 \mathrm{~h}$ ) by increasing the concentration of sodium hydroxide in the presence of ethanol and water. In contrast, gelation did not occur in the absence of sodium hydroxide or water or in the presence of acidic solutions. Delayed gelation ( $96 \mathrm{~h}$ to $120 \mathrm{~h}$ ) occurred as a result of the introduction of dipotassium hydrogen phosphate trihydrate. Superhydrophobic powder was obtained by the evaporation of solvents from the gelated sol at $150{ }^{\circ} \mathrm{C}$. The surface properties of the superhydrophobic powder were examined by scanning electron microscopy, high resolution transmission electron microscopy, $\mathrm{N}_{2}$ sorption isotherm, and X-ray diffraction. The particle size, functional groups and thermal stability of the powder were analyzed by dynamic light scattering spectroscopy, Fourier transform infrared spectroscopy, ${ }^{29} \mathrm{Si}$ cross polarization magic angle spinning nuclear magnetic resonance spectroscopy, and thermogravimetric analysis. The surface properties of the powder were also assessed by contact angle measurements. The results showed that increasing the concentration of sodium hydroxide added to PMHS or increasing the drying temperature of the gelated sol resulted in the more rapid formation of superhydrophobic powder.
\end{abstract}

\begin{abstract}
Received on 04-04-2014 Accepted on 27-06-2014 Published on 30-10-2014
\end{abstract}

Keywords: Superhydrophobic, polymethylhydrosiloxane, sodium hydroxide, synthesis, powder.

\section{INTRODUCTION}

The wettability of a solid surface is defined by its ability to be wetted or dewetted by the contact of a liquid water droplet. Based on the wettability phenomena, the surface properties of a solid substrate can be classified as superhydrophilic, hydrophilic, hydrophobic and superhydrophobic according to their contact angles (CAs) [1]. A substrate surface with very low $C A\left(<5^{\circ}\right)$ is defined as a superhydrophilic surface. A substrate surface with CA less than $90^{\circ}$, and $90^{\circ}$ to $150^{\circ}$ and greater than $150^{\circ}$ are defined as hydrophilic, hydrophobic and superhydrophobic or self-cleaning surfaces, respectively [1-3]. Over the recent decade, superhydrophobic surfaces have found many applications, such as the adsorption and separation of oils from water, cultivation of micro-organisms, photocatalysis, anti-reflective coating, moisture resistant surfaces, sensors, and other applications, because of their non-stick and self-cleaning properties [4-8]. Superhydrophobic powders have recently begun to play a vital role in several applications, such as the formation of liquid marbles, superhydrophobic magnetic particles and bio-medical applications [9-12]. These types of superhydrophobic

"Department of Polymer Science and Engineering, Pusan National University, Busan 609-735, Korea; Tel: +82-51-510-2407; Fax: +82-51-514-4331;

E-mail: csha@pnu.edu,csha@pusan.ac.kr surfaces and materials are prepared using several methods, such as top-down, bottom-up and combinations of top-down and bottom-up approaches [4, 13]. A wide range of superhydrophobic surfaces have been prepared using these approaches and some have been commercialized.

Several factors were considered when synthesizing superhydrophobic materials or fabricating superhydrophobic surfaces based on the above methods. Recently, sol-gel method has attracted considerable attentions for the superhydrophobic surface fabrication. This is mainly due to the simple synthesis of superhydrophobic material by hydroxylation and condensation of silane precursors and easy fabrication of superhydrophobic surface by various coating methods such as dip coating, spin coating, casting, spraying, and drop coating, etc. Meanwhile, optimization of the material by sol-gel method is the most important criteria to fabricate uniform surface phenomena. The optimization of sol-gel methods depends on the kinds of silane precursors, catalyst, stirring time, rotation speed, reaction conditions (temperature, oil or water bath), and drying temperature etc. [14]. In this work, superhydrophobic powder was synthesized by self-hydroxylation and condensation of polymethylhydrosiloxane (PMHS) using sodium hydroxide solutions $\left(\mathrm{NaOH} / \mathrm{H}_{2} \mathrm{O}\right)$ as a catalyst in the presence of ethanol by referring to previous studies $[5,15]$. 
Table 1: Synthesis of Superhydrophobic Powders under Various Concentrations of Catalysts

\begin{tabular}{|c|c|c|c|c|c|c|c|c|}
\hline $\begin{array}{l}\text { Sample } \\
\text { Name }\end{array}$ & $\begin{array}{l}\text { PMHS } \\
\text { (g) }\end{array}$ & $\begin{array}{c}\text { Ethanol } \\
(\mathrm{mL})\end{array}$ & $\begin{array}{c}\mathrm{NaOH} \\
(\mathrm{g})\end{array}$ & $\begin{array}{c}\mathrm{K}_{2} \mathrm{HPO}_{4} \cdot 3 \mathrm{H}_{2} \mathrm{O} \\
\text { (g) }\end{array}$ & $\begin{array}{l}\text { Aq. Ammonia } \\
(\mathrm{mL})\end{array}$ & $\mathrm{HCl}(\mathrm{mL})$ & $\begin{array}{l}\mathrm{H}_{2} \mathrm{O} \\
(\mathrm{mL})\end{array}$ & $\begin{array}{l}\text { Gelation Time } \\
\text { (hr) }\end{array}$ \\
\hline PS1 & 4.7 & 70 & 0.008 & - & - & - & 2 & 8 \\
\hline PS2 & 4.7 & 70 & 0.016 & - & - & - & 2 & 6 \\
\hline PS3 & 4.7 & 70 & 0.024 & - & - & - & 2 & 5 \\
\hline PS4 & 4.7 & 70 & 0.032 & - & - & - & 2 & 3 \\
\hline PS5 & 4.7 & 70 & 0.04 & - & - & - & 2 & 2 \\
\hline PK1 & 4.7 & 70 & - & 0.05 & - & - & 2 & $96-120$ \\
\hline PK3 & 4.7 & 70 & - & 0.14 & - & - & 2 & $96-120$ \\
\hline PK5 & 4.7 & 70 & - & 0.23 & - & - & 2 & $96-120$ \\
\hline PA1 & 4.7 & 70 & - & & 0.12 & - & 9.88 & - \\
\hline PA2 & 4.7 & 70 & - & & 0.24 & - & 9.76 & - \\
\hline PA3 & 4.7 & 70 & - & & 0.36 & - & 9.64 & - \\
\hline PH1 & 4.7 & 70 & - & & - & 0.1 & 9.90 & - \\
\hline $\mathrm{PH} 2$ & 4.7 & 70 & - & & - & 0.2 & 9.80 & - \\
\hline $\mathrm{PH} 3$ & 4.7 & 70 & - & & - & 0.3 & 9.70 & - \\
\hline
\end{tabular}

${ }^{*} \mathrm{~S}, \mathrm{~K}, \mathrm{~A}$ and $\mathrm{H}$ represent the presence of $\mathrm{NaOH}, \mathrm{K}_{2} \mathrm{HPO}_{4} \cdot 3 \mathrm{H}_{2} \mathrm{O}$, aqueous ammonia and $\mathrm{HCl}$, respectively.

PMHS is a siloxane-based transparent liquid with potential use in a wide range of applications owing to its high thermal stability, inertness to air and moisture, solubility in common organic solvents, hydrophobicity, and low surface energy [1618]. Some uses of PMHS include superhydrophobic materials, catalysis, preparation of highly transparent and anti-stain substrates, liquid crystalline polymers (LCPs), ceramics, and the formation of nano necklaces $[5,9,15,19$ 23]. Despite of several advantages of PMHS, to the best of authors' knowledge, the use of PMHS for the synthesis of superhydrophobic materials and their uses for practical applications were limited [5, 24, 25]. Yang et al. synthesized superhydrophobic powder by using PMHS and tetraethoxysilane (TEOS) in the presence of $\mathrm{NaOH} /$ water and ethanol [9]. They checked the adsorption behaviour of superhydrophobic powder for the adsorption of traces of alkylphenols in water [25]. Zhai et al. also prepared a similar type of superhydrophobic mesoporous xerogel powder using PMHS and bridged bis-(triethoxysilyl)etane (BTME) in the presence of $\mathrm{NaOH} /$ water and ethanol [26]. The superhydrophobic powders were obtained with the total time of 3-5 days [9, 25, 26]. Our previous study also showed that it took almost 2-3 days to synthesize polymethylhydroxysiloxane (PMHOS) powder even by one-pot approach [5]. The effect of catalysts and the effect of drying temperature were not discussed elsewhere for the PMHS under self-hydroxylation and condensation. Due to the excellent thermal stability of the superhydrophobic powder, increasing the drying temperature would reduce the material synthesis time. Based on the above concepts, we examined the effects of sodium hydroxide solutions for the rapid synthesis of superhydro- phobic powder from PMHS [5, 15]. Increasing the concentration of $\mathrm{NaOH}$ to PMHS led to faster the gelation time from $8 \mathrm{~h}$ to $2 \mathrm{~h}$. In this work, solvents were evaporated after the complete condensation of PMHOS by keeping the self-hydrolyzed and condensed sol for $24 \mathrm{~h}$ of total reaction time. On the other hand, the drying temperature was increased from $80{ }^{\circ} \mathrm{C}$ to $150{ }^{\circ} \mathrm{C}$ and the drying time was reduced from 24-30 $\mathrm{h}$ to 2-4 $\mathrm{h}$. Hence, the changes in the surface properties of a superhydrophobic powder by increasing the concentration of a sodium hydroxide solution or by increasing the drying temperature to $150{ }^{\circ} \mathrm{C}$ were investigated in this work. The main advantage of the study illustrates the faster synthesis of superhydrophobic powder by the increase of catalyst concentrations and drying temperature over other processes reported elsewhere. Moreover, the superhydrophobic powder can also be prepared rapidly by the evaporation of solvent after the complete gelation ( $2 \mathrm{~h}$ or $8 \mathrm{~h}$ ). The effects of other basic and acidic solutions for the synthesis were also checked based on the experimental procedure.

\section{EXPERIMENTAL DETAILS}

\subsection{Materials}

PMHS (Mn 1700 to 3200) and dipotassium hydrogen phosphate trihydrate $\left(\mathrm{K}_{2} \mathrm{HPO}_{4} .3 \mathrm{H}_{2} \mathrm{O}\right)$ were acquired from Sigma-Aldrich. Anhydrous ethanol (special grade) was obtained from Carlo Erba Reagents Co. Ltd. Sodium hydroxide $(\mathrm{NaOH})$ and ammonia solution $\left(\mathrm{NH}_{3}, 28-30 \%\right.$ $(\mathrm{m} / \mathrm{m})$ ) were purchased from Junsei Chemical Co. Ltd. 


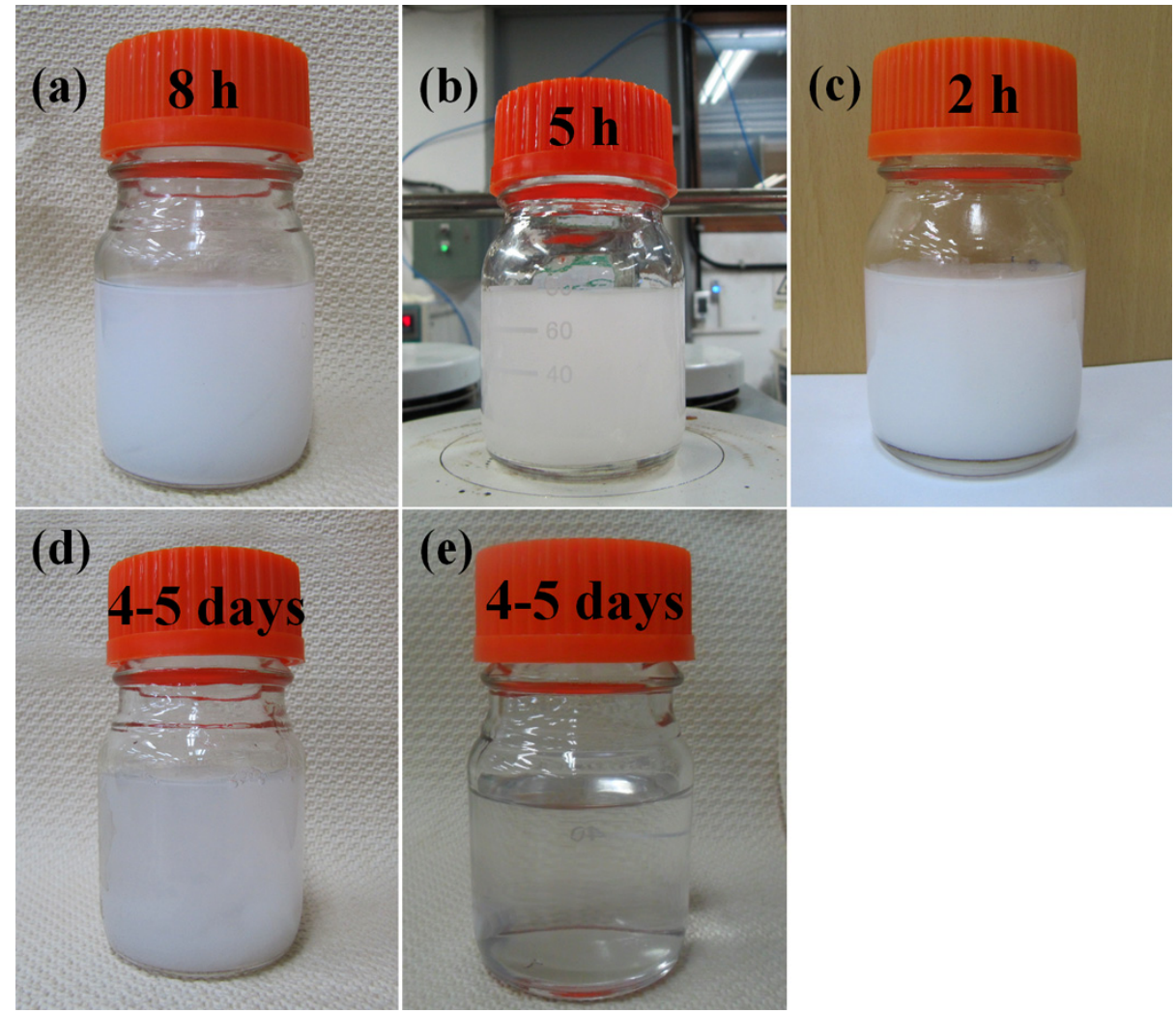

Figure 1: Optical images of PMHS after adding various concentrations of $\mathrm{NaOH}(\mathrm{PS} 1$ (a), $\mathrm{PS} 3(\mathbf{b})$ and $\mathrm{PS} 5(\mathbf{c})), \mathrm{K}_{2} \mathrm{HPO}_{4} .3 \mathrm{H}_{2} \mathrm{O}(\mathrm{PK} 5(\mathbf{d}))$ and $\mathrm{HCl}(\mathrm{PH} 1(\mathbf{e}))$ in ethanol/water medium.

Hydrochloric acid $(\mathrm{HCl})$ (Guaranteed reagents) was supplied by Matsunoen Chemicals Ltd. Double deionized water was used in all experiments.

\subsection{One-Spot Synthesis of Superhydrophobic Polyme- thylhydroxysiloxane}

PMHS (4.7 g, $78 \mathrm{mmol}$ MeHSiO) was dissolved in anhydrous ethanol $(70 \mathrm{~mL})$ in a $100 \mathrm{~mL}$ glass container and hydrolyzed by the addition of a sodium hydroxide $(0.2 \mathrm{mmol}$ in $2 \mathrm{~mL}$ of water) solution $[5,15]$. The hydrolyzed sol was gelated in $8 \mathrm{~h}$ and stirred further for a total stirring time of $24 \mathrm{~h}$ (Figure 1 and Table 1). The gel was condensed further and dried at $150{ }^{\circ} \mathrm{C}$ for $2 \mathrm{~h}$. The superhydrophobic product was ground to a powder, washed several times in deionized water and dried for a further $2 \mathrm{~h}$ at $150{ }^{\circ} \mathrm{C}$, followed grinding to a fine powder. The experiment was repeated with various $\mathrm{NaOH}$ ratios $(0.4$ $\mathrm{mmol}, 0.6 \mathrm{mmol}, 0.8 \mathrm{mmol}$ and $1.0 \mathrm{mmol}$ ) or $\mathrm{K}_{2} \mathrm{HPO}_{4} .3 \mathrm{H}_{2} \mathrm{O}$ (0.2 mmol, $0.5 \mathrm{mmol}$ and $1.0 \mathrm{mmol}$ ) or with aqueous ammonia $(0.1 \mathrm{M}, 0.3 \mathrm{M}$ and $0.5 \mathrm{M}, 2 \mathrm{~mL}$ of $10 \mathrm{~mL}$ of ammonia/water solution) and $\mathrm{HCl}(0.1 \mathrm{M}, 0.3 \mathrm{M}$ and $0.5 \mathrm{M}, 2$ $\mathrm{mL}$ of $10 \mathrm{~mL}$ of $\mathrm{HCl} /$ water solution) solutions (Table 1). The gelation of sol became faster from 8 to $2 \mathrm{~h}$ by increasing the concentration of $\mathrm{NaOH}(0.4 \mathrm{mmol}(6 \mathrm{~h}), 0.6 \mathrm{mmol}(5 \mathrm{~h}), 0.8$ $\mathrm{mmol}(3 \mathrm{~h})$, and $1.0 \mathrm{mmol}(2 \mathrm{~h}))$. The gel was condensed further to form complete siloxane networks with the total time of $24 \mathrm{~h}$ and then dried at $150{ }^{\circ} \mathrm{C}$ based on the experimental procedure and repeated washing and drying processes. The experiment was also repeated in the absence of $\mathrm{NaOH}$ and water. Table 1 provides more details on the synthesis of superhydrophobic powders. The synthesized superhydrophobic powder is referred to as PMHOS or $P$. The synthesized powder is also called PS1-PS5, PK1, PK3, PK5, PA1-PA3, and $\mathrm{PH} 1-\mathrm{PH} 3$, based on the concentrations of the basic and acidic solutions, where $\mathrm{S}, \mathrm{K}, \mathrm{A}$ and $\mathrm{H}$ indicate the presence of $\mathrm{NaOH}, \mathrm{K}_{2} \mathrm{HPO}_{4} \cdot 3 \mathrm{H}_{2} \mathrm{O}$, aqueous ammonia, and $\mathrm{HCl}$, respectively.

\subsection{Characterization}

The surface morphology of the superhydrophobic powder was examined by scanning electron microscopy (SEM, Table-top Mini, SNE-3000M). The samples were placed on a carbon tape and coated with gold before the measurements. The material surface was also examined by high resolution transmission electron microscopy (HR-TEM, JEM 2011 at $200 \mathrm{kV}$ ). PMHOS was dispersed well by ultra sonication for $60 \mathrm{~min}$. in ethanol and collected on a copper grid before the measurement. The particle surface area, pore volume and pore diameter were measured by a Micromeritics ASAP 2020 V3.04 G surface area and pore size analyzer, and calculated using the Brunauer-Emmett-Teller (BET) method and Barrett-Joyner-Halenda (BJH) analysis [27]. The structural properties of the particles were analyzed by X-ray diffraction (XRD) using a Miniflex goniometer at a scanning range from $1.2^{\circ}-80^{\circ} 2 \theta$. Dynamic light scattering (DLS, Zeta sizer, Nano S90) was used to measure the particle size of the samples. Before the measurements, the superhydrophobic powder was 
dispersed well in ethanol for $24 \mathrm{~h}$. The functional groups present in the superhydrophobic powder were analyzed by Fourier transform infrared (FTIR, JASCO (FTIR-4100)) spectroscopy and ${ }^{29} \mathrm{Si}$ cross polarization magic angle spinning nuclear magnetic resonance $\left({ }^{29} \mathrm{Si} C P\right.$ MAS NMR) spectroscopy using a $400 \mathrm{MHz}$ Avance II+ Bruker Solid-state NMR at the Korea Basic Science Institute (KBSI) Daegu Centre. The thermal stability of the superhydrophobic powder was estimated by thermogravimetric analysis (TGA, Q50 V6.2, Build 187, TA instruments, U.S) in a nitrogen atmosphere at a heating rate at $10^{\circ} \mathrm{C} / \mathrm{min}$. The superhydrophobic powder dispersed in ethanol was coated on a glass substrate and the surface properties of the coated powder were examined by contact angle (CA) measurements using a drop shape analysis system (DSA 100, Krüss GmbH, Germany)). The measurements were carried out in $500 \mu \mathrm{L}$ syringe with a needle, $0.5 \mathrm{~mm}$ in diameter and $38 \mathrm{~mm}$ in length with a liquid volume of $8 \mu \mathrm{L}$ under a flow rate of 600 rpm [28].

\section{RESULTS AND DISCUSSION}

A previous study revealed the gelation of PMHS in the presence of $\mathrm{NaOH}$ in ethanol/water medium. The PMHOS powder (in $\mathrm{NaOH}\left(0.2 \mathrm{mmol}\right.$ ) at $80{ }^{\circ} \mathrm{C}$ ) obtained from the gel showed a micro-nano hierarchical surface morphology with superhydrophobicity [5]. The results in the current study revealed the effect of $\mathrm{NaOH}$ and water on the gelation of PMHS through self hydroxylation and condensation. The hydrolysis and condensation of PMHS by the addition of $\mathrm{NaOH}$ in ethanol medium would deliver the exchange of ethoxy and hydroxy groups with the highly reactive $\mathrm{Si}-\mathrm{H}$ groups in PMHS [9]. Under this condition, PMHOS forms a helical structure with hydrophobic methyl and hydrophilic hydroxy groups at the inner and outer loop of the material surface. Further condensation occurred in the siloxane chains through the evaporation of the solvents from the sol at $150{ }^{\circ} \mathrm{C}$ for $2 \mathrm{~h}$, which leads to the production of stronger hydrophobic methyl groups on the surface. The superhydrophobic property was obtained by washing the sample in an excess of water and dried again at $150{ }^{\circ} \mathrm{C}$ for $2 \mathrm{~h}[5,9,15]$. Increasing the $\mathrm{NaOH}$ concentration (from $0.2 \mathrm{mmol}$ to $1 \mathrm{mmol}$ ) to the PMHS accelerated gelation from $8 \mathrm{~h}$ to $2 \mathrm{~h}$ (Figure 1a-c). Similarly, increasing the drying temperature of the gelated sol from $80{ }^{\circ} \mathrm{C}$ to $150{ }^{\circ} \mathrm{C}$ reduced the synthesis time of the superhydrophobic powder from 2-3 days to 1-2 days. On the other hand, gelation did not occur in the absence of $\mathrm{NaOH}$ or water. The effects of $\mathrm{NaOH}$ over other basic and acidic solutions on the synthesis of the superhydrophobic powder were examined (Table 1). The addition of $\mathrm{K}_{2} \mathrm{HPO}_{4} \cdot 3 \mathrm{H}_{2} \mathrm{O}$ (in ethanol and water) can allow the slow formation of a sol, followed by gelation in 96-120 h. PMHS could not form a sol or gel in the presence of aqueous ammonia or $\mathrm{HCl}$. The results clearly show that $\mathrm{NaOH}$ plays a major role in the solgel behavior and accelerate the gelation of PMHS over other basic and acidic solutions.

Figure 2 shows the surface morphology of PMHOS synthesized from various $\mathrm{NaOH}$ and $\mathrm{K}_{2} \mathrm{HPO}_{4} \cdot 3 \mathrm{H}_{2} \mathrm{O}$ concentrations. PS1 showed similar micro-nano hierarchical surface properties and superhydrophobicity to those obtained at $80{ }^{\circ} \mathrm{C}$ in a previous study (Figure 2a) [5]. The surface properties were altered partially by increasing the $\mathrm{NaOH}$ concentration (Figure 2a-e). On the micro scale, the PS1-PS5 samples showed a flake-like morphology of layered networks of siloxane chains (Figure 2a-e). The layered networks of the siloxane chains increased with increasing $\mathrm{NaOH}$ concentration (Figure 2). A flake-like morphology was also obtained for the material prepared using $\mathrm{K}_{2} \mathrm{HPO}_{4} .3 \mathrm{H}_{2} \mathrm{O}$ (PK5) (Figure 2f). The SEM images illustrate the formation of hierarchical surface morphology of the micro-nanoparticles of PMHOS. This hierarchical micro-nano surface morphology
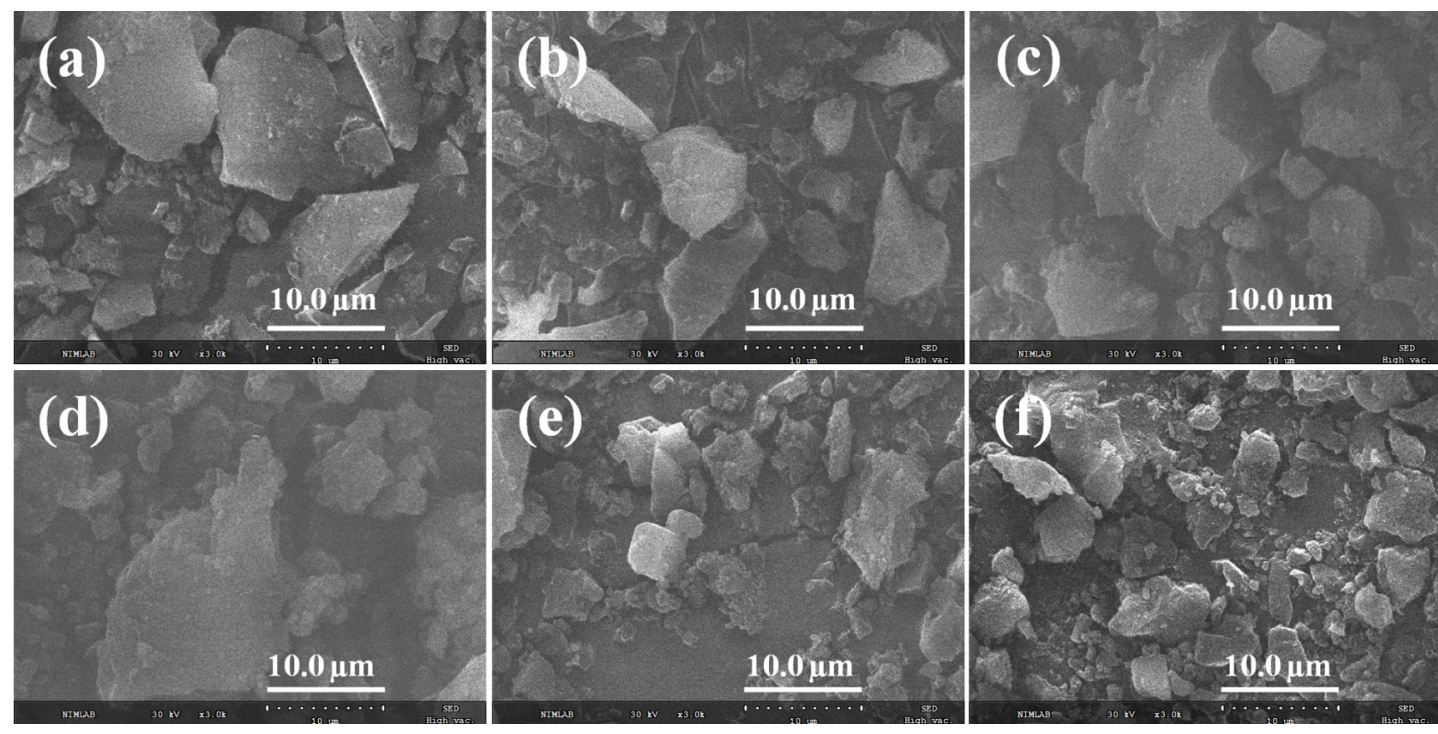

Figure 2: SEM images of the synthesized superhydrophobic powder obtained with various concentrations of $\mathrm{NaOH}$ ((a) PS1, (b) PS2, (c) PS3, (d) PS4, (e) PS5), and $\mathrm{K}_{2} \mathrm{HPO}_{4} \cdot 3 \mathrm{H}_{2} \mathrm{O}$ ((f) PK5). 


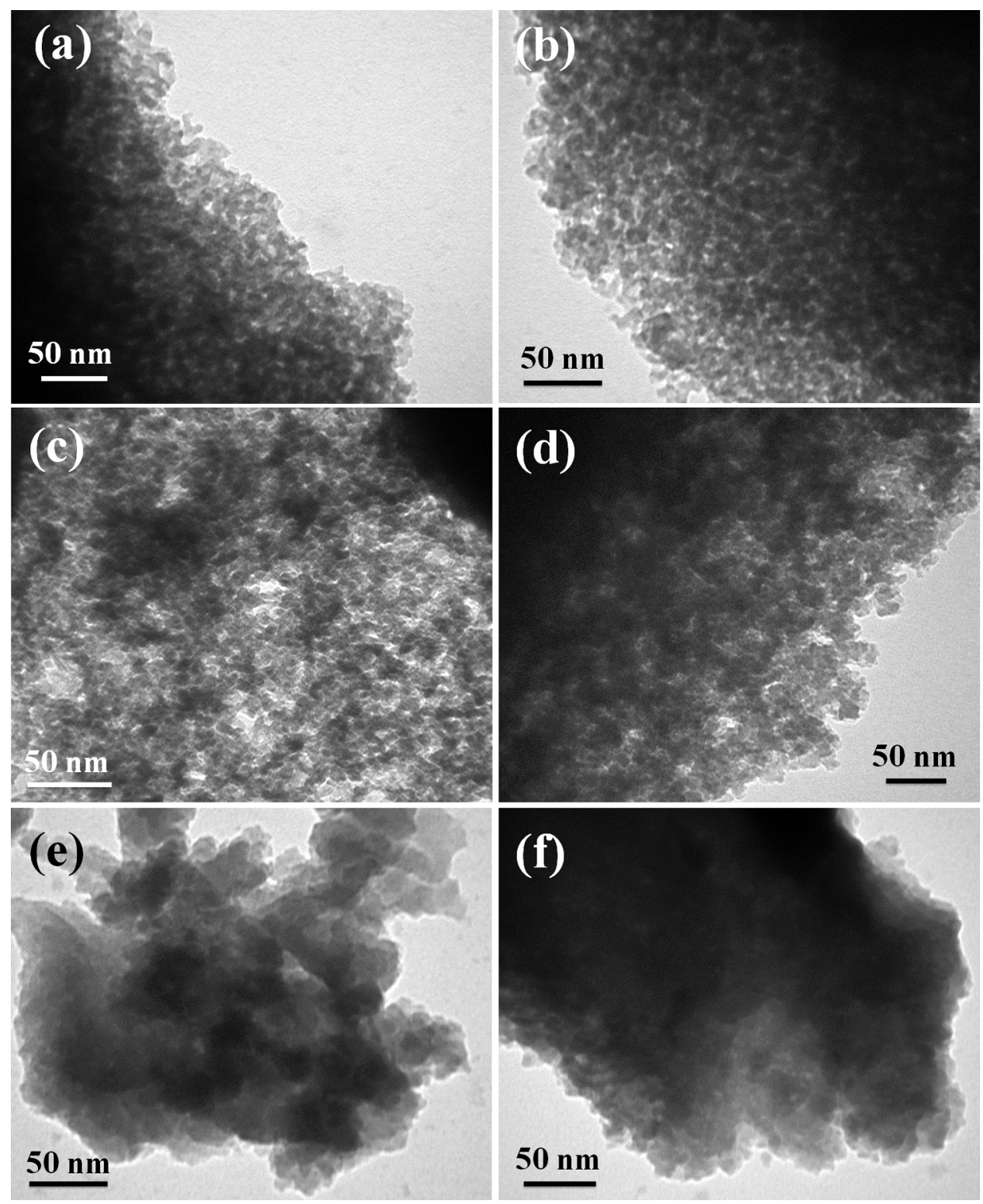

Figure 3: HR-TEM images of the synthesized superhydrophobic powder obtained with various concentrations of $\mathrm{NaOH}((\mathbf{a}) \mathrm{PS} 1,(\mathbf{b}) \mathrm{PS} 2$, (c) PS3, (d) PS4, (e) PS5), and $\mathrm{K}_{2} \mathrm{HPO}_{4} \cdot 3 \mathrm{H}_{2} \mathrm{O}((\mathbf{f}) \mathrm{PK} 5)$.

with hydrophobic methyl groups anchored on the surface would maintain the stable superhydrophobicity of the material surface when coating the dispersed suspension on a glass substrate. The HRTEM images of the PS1-PS5 samples revealed a porous structure of the hierarchical micronanoparticle (Figure 3a-e). The porous structure of the material was mainly due to the formation of siloxane networks of the PMHS under self hydroxylation and condensation. On the other hand, the porous structure of the material was changed significantly by increasing the $\mathrm{NaOH}$ concentration as well as curing the gel at $150{ }^{\circ} \mathrm{C}$ [5]. The changes in the morphology of the samples were attributed to the faster gelation of the material. Increasing the concentration of $\mathrm{NaOH}$ from $0.2 \mathrm{mmol}$ to $0.4 \mathrm{mmol}$ and $0.6 \mathrm{mmol}$, the surface area and pore diameter were increased. The HRTEM images of PMHOS prepared with $0.4 \mathrm{mmol}$ and $0.6 \mathrm{mmol}$ of $\mathrm{NaOH}$ also showed the enhanced porous morphologies of the samples (Figure 3a-c). This could be confirmed further by BET sorption analysis. The porous structure of the materials was reduced by further increasing the concentration of $\mathrm{NaOH}$ from $0.6 \mathrm{mmol}$ to $1 \mathrm{mmol}$. The results indicated that the addition of up to $0.6 \mathrm{mmol}$ (PS3) of $\mathrm{NaOH}$ in $2 \mathrm{~mL} \mathrm{H}_{2} \mathrm{O}$ would be a sufficient amount for the synthesis of superhydrophobic powder. The change in surface morphology was also obtained when higher $\mathrm{K}_{2} \mathrm{HPO}_{4} \cdot 3 \mathrm{H}_{2} \mathrm{O}$ concentrations were used (PK5) (Figure $\mathbf{3 f}$ ). The porous structure of PMHOS was reduced by the addition of $\mathrm{K}_{2} \mathrm{HPO}_{4} .3 \mathrm{H}_{2} \mathrm{O}$ solution instead of $\mathrm{NaOH}$ solution. The obtained surface of the material showed thick layers of the siloxane networks of the material (Figure 3f). The DLS spectra indicated a change in the particle size by the increase in $\mathrm{NaOH}$ concentration. At lower $\mathrm{NaOH}$ concentrations (PS1), the spectrum revealed a dual (micro and nano) particle size (Figure 4A, Table 2). The main cause of such a dual particle size might the complexity arising from 
the difference in the rate of particle gelation as well as the self-hydrolysis and condensation rates of PMHS, depending on the concentration of either $\mathrm{NaOH}$ or $\mathrm{K}_{2} \mathrm{HPO}_{4} \cdot 3 \mathrm{H}_{2} \mathrm{O}$. On the other hand, the mean particle size of the sample increased with increasing $\mathrm{NaOH}$ concentration [29, 30]. At higher $\mathrm{NaOH}$ concentrations (PS5), the particle size of the superhydrophobic powder increased to a micrometer size (Figure 4A, Table 2). A higher $\mathrm{NaOH}$ concentration and faster gelation of the siloxane backbone might increase the particle size of the final material, whereas increasing the concentration of $\mathrm{NaOH}$ might twist the hydrophobic and hydrophilic substitutions in the cross-linked siloxane chain towards the surface via a hydroxylation and condensation reaction. At higher $\mathrm{NaOH}$ concentrations, PMHS favors the formation of hydrophilic groups on the PMHOS surface, which is due to electrostatic attractions between PMHOS and $\mathrm{NaOH}$ and the possibilities of exchanging the ethoxy groups in ethanol. On the other hand, the strongly hydrophobic methyl groups maintain the hydrophobicity of the material. Superhydrophobicity was obtained by washing the sample in an excess of water followed by drying at $150{ }^{\circ} \mathrm{C}$. During the gelation and cocondensation stage, the surface properties of the material were changed significantly and the particle size increased. In contrast, the dual micro-nano particle sizes of the samples were reduced by increasing the concentration of $\mathrm{K}_{2} \mathrm{HPO}_{4} \cdot 3 \mathrm{H}_{2} \mathrm{O}$ added to the PMHS (Figure 4 and Table 2). These conflicting properties were attributed mainly to the gelation effect of $\mathrm{NaOH}$ and $\mathrm{K}_{2} \mathrm{HPO}_{4} \cdot 3 \mathrm{H}_{2} \mathrm{O}$ with PMHS. $\mathrm{NaOH}$ is more favorable and easily hydrolyzed the PMHS in ethanol/water medium than $\mathrm{K}_{2} \mathrm{HPO}_{4} \cdot 3 \mathrm{H}_{2} \mathrm{O}$.

Figure 5 shows XRD patterns of PMHOS synthesized using various concentrations of $\mathrm{NaOH}$. PMHOS showed two important peaks (sharp and broad) at $9.36^{\circ} 2 \theta$ (003 plane) and at 16.11 to $30.50^{\circ} 2 \theta$, indicating the crystalline and amorphous peaks of alkyl chain present at the siloxane backbone, respectively [5]. The sharp peak at $9.36^{\circ} 2 \theta$ shifted towards a higher angle $10.51^{\circ} 2 \theta$ and became identical by increasing the $\mathrm{NaOH}$ concentration. The obtained results suggest that a significant change in the superhydrophobic material by increasing the concentration of $\mathrm{NaOH}$. Figure 6 shows the $\mathrm{N}_{2}$ adsorption and desorption isotherms, pore volumes and pore size distributions of the synthesized superhydrophobic PMHOS. The superhydrophobic powder showed a $\mathrm{H}_{2}$ hysteresis loop with a type IV isotherm peak, indicating the disordered mesoporous structure of PMHOS [22]. A previous study also revealed the disordered mesoporous structure of PMHOS synthesized at a
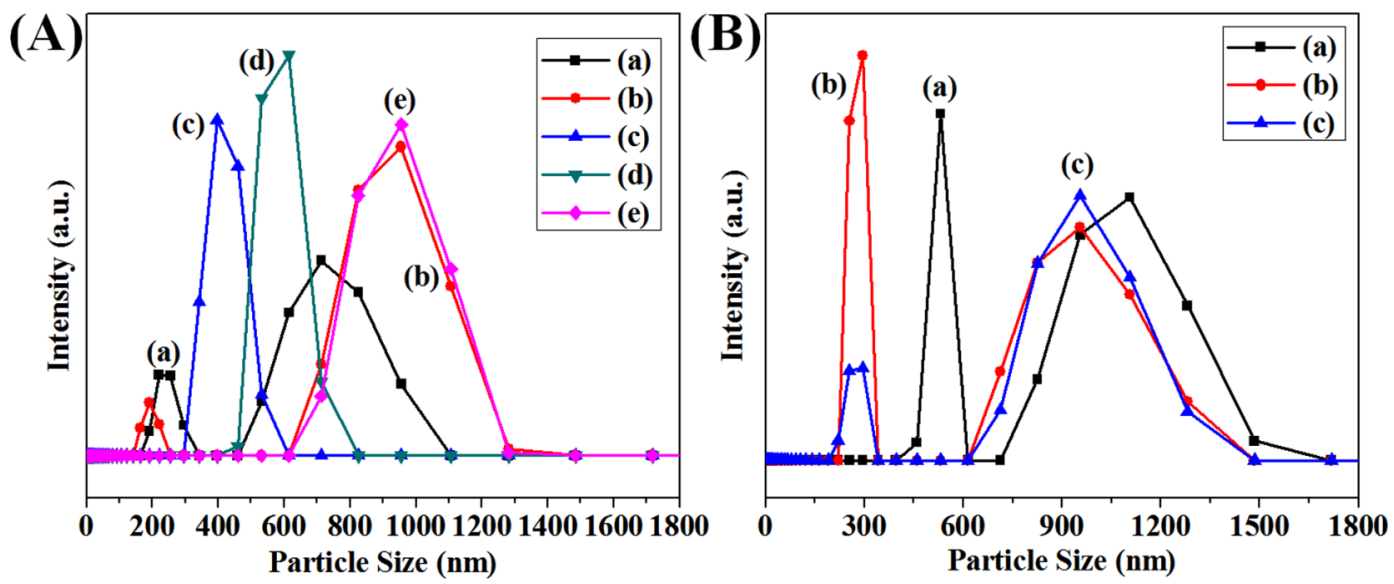

Figure 4: DLS particle size spectra of the synthesized superhydrophobic powder obtained with various concentrations of $\mathrm{NaOH}$ ((A) PS1 (a), PS2 (b), PS3 (c), PS4 (d) and PS5 (e)), and $\mathrm{K}_{2} \mathrm{HPO}_{4} \cdot 3 \mathrm{H}_{2} \mathrm{O}((\mathbf{B}) \mathrm{PK} 1(\mathbf{a}), \mathrm{PK} 3(\mathbf{b})$ and PK5 (c))).

Table 2: DLS Particle Size Data of Superhydrophobic Powder Obtained at Various Concentrations of $\mathrm{NaOH}_{\text {and }} \mathrm{K}_{2} \mathrm{HPO}_{4} \cdot 3 \mathrm{H}_{2} \mathrm{O}$

\begin{tabular}{|c|c|c|}
\hline Sample Name & \multicolumn{2}{|c|}{ Dual Particle Size } \\
\hline & Micro Particle Size (nm) & 240 \\
\hline PS1 & 731 & 192 \\
\hline PS2 & 957 & 397 \\
\hline PS3 & - & - \\
\hline PS4 & 609 & - \\
\hline PS5 & 957 & 534 \\
\hline PK1 & 1104 & 292 \\
\hline PK3 & 957 & 270 \\
\hline PK5 & 957 & \\
\hline
\end{tabular}




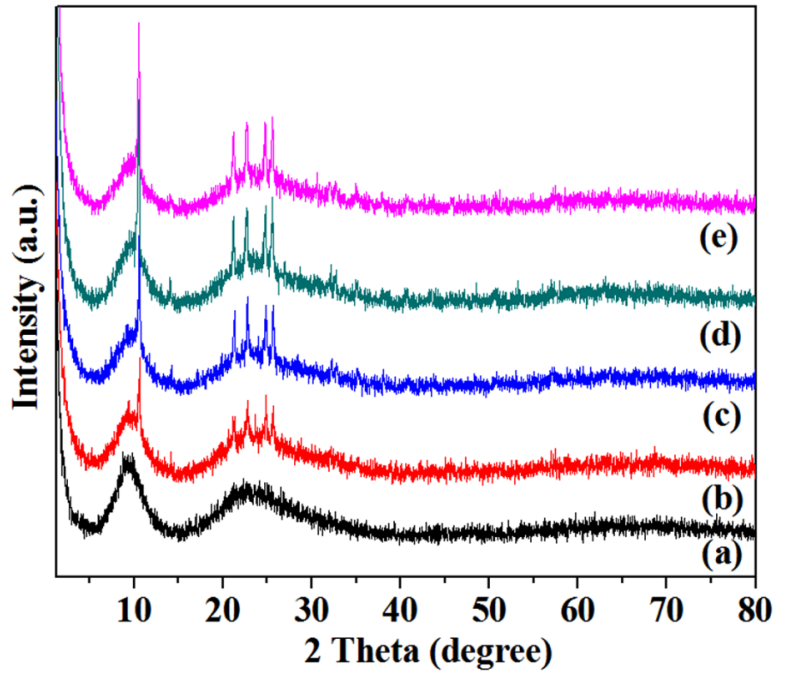

Figure 5: XRD patterns of the synthesized superhydrophobic powder obtained with various concentrations of $\mathrm{NaOH}$ ((a) PS1, (b) PS2, (c) PS3, (d) PS4 and (e) PS5).

drying temperature of $80^{\circ} \mathrm{C}$ with a surface area, pore volume and pore diameter of $413 \mathrm{~m}^{2} / \mathrm{g}, 1.08 \mathrm{~cm}^{3} / \mathrm{g}$ and $25.1 \mathrm{~nm}$, respectively [5]. On the other hand, the surface area (334 $\left.\mathrm{m}^{2} / \mathrm{g}\right)$, pore volume $\left(0.33 \mathrm{~cm}^{3} / \mathrm{g}\right)$ and pore diameter $(5.5 \mathrm{~nm})$ were lower when the drying temperature of the gelated sol was higher (see Table 3). Increasing the concentration of $\mathrm{NaOH}$ added to the PMHS showed an increasing trend in the

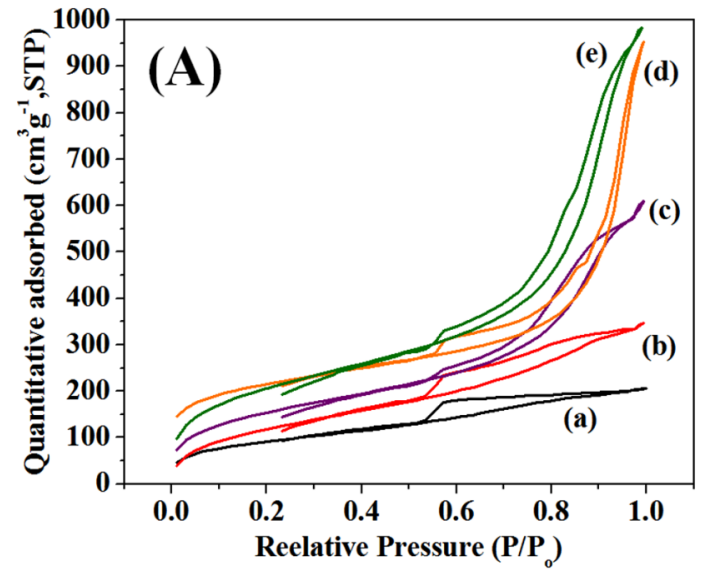

surface area, pore volume and pore diameter of the samples, even though the trend in the surface area was not consistent. HRTEM images also agreed with the change in surface properties of the superhydrophobic powder by increasing the concentration of $\mathrm{NaOH}$ (Figure 3). The results showed that both the $\mathrm{NaOH}$ concentration and drying temperature play key roles in controlling the surface area, pore volume and pore diameter, but the precise mechanism is unclear.

FTIR spectroscopy showed the important peaks of PMHS, such as $\mathrm{Si}-\mathrm{H}, \mathrm{Si}-\mathrm{O}-\mathrm{Si}$ and $\mathrm{Si}-\mathrm{CH}_{3}$ at $2170 \mathrm{~cm}^{-1}, 1030-1130$ $\mathrm{cm}^{-1}$ and $1260 \mathrm{~cm}^{-1}$ (Figure 7a), respectively [20, 21]. The disappearance of a Si-H peak at $2170 \mathrm{~cm}^{-1}$ and the splitting of the Si-O-Si peaks to $1037 \mathrm{~cm}^{-1}$ and $1122 \mathrm{~cm}^{-1}$ confirmed the self-hydroxylation and condensation of PMHS under $\mathrm{NaOH}$ (Figure 7b) [5]. Si-OH peaks were observed at $3437 \mathrm{~cm}^{-1}$ and $910 \mathrm{~cm}^{-1}$ and $\mathrm{Si}-\mathrm{CH}_{3}$ peaks were noted at $2973 \mathrm{~cm}^{-1}, 2916$ $\mathrm{cm}^{-1}, 1273 \mathrm{~cm}^{-1}, 847 \mathrm{~cm}^{-1}$, and $777 \mathrm{~cm}^{-1}$. The results suggest that the addition of $\mathrm{NaOH}$ cause a significant change in the functional groups (Figure $\mathbf{7 a}$ and $\mathbf{b}$ ). On the other hand, increasing the $\mathrm{NaOH}$ concentration also showed similar peaks to those obtained at the initial $\mathrm{NaOH}$ concentration (Figure 7b-f). ${ }^{29}$ Si-NMR spectroscopy also confirmed the above concept of similar functional groups $\left(\mathrm{T}^{3}(-59.6 \mathrm{ppm}), \mathrm{T}^{2}\right.$ $(-55.9 \mathrm{ppm})$ and $\left.\mathrm{M}^{1}(8.14 \mathrm{ppm})\right)$ after increasing the $\mathrm{NaOH}$ concentration or by the addition of $\mathrm{K}_{2} \mathrm{HPO}_{4} .3 \mathrm{H}_{2} \mathrm{O}$ (Figure 8) [5]. A peak at -20.7 ppm in PS1 might be due to the presence of impurities and the noise peak of the sample. On the other

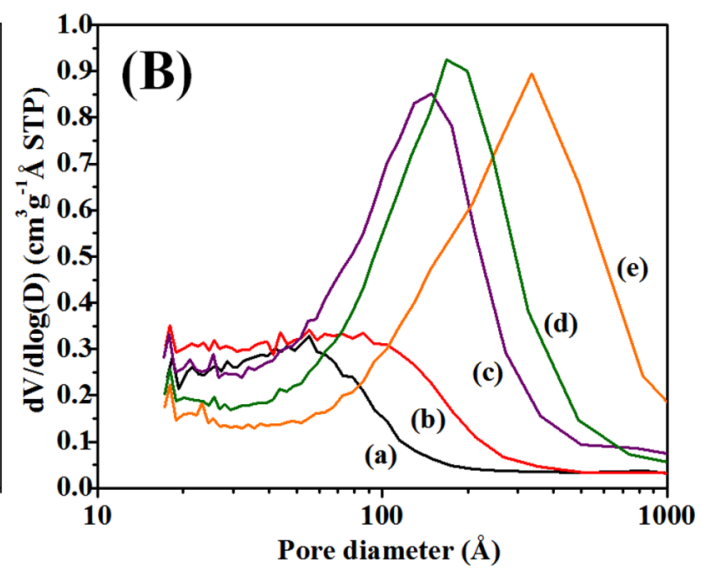

Figure 6: $((A)$ and $(B)) N_{2}$ adsorption and desorption isotherms and pore size distributions curves of the synthesized superhydrophobic powder obtained with various concentrations of $\mathrm{NaOH}$ ((a) PS1, (b) PS2, (c) PS3, (d) PS4, and (e) PS5).

Table 3: $\quad$ BET Surface Areas and Pore Size Distributions of the Superhydrophobic Powders Prepared at Various Concentrations of $\mathrm{NaOH}$

\begin{tabular}{|c|c|c|c|}
\hline Sample & $\begin{array}{c}\text { BET surface } \\
\text { Area }\left(\mathbf{m}^{2} \mathbf{g}^{-1}\right)\end{array}$ & $\begin{array}{c}\text { Total pore } \\
\text { Volume }\left(\mathbf{c m}^{\mathbf{3}} \mathbf{g}^{-1}\right)\end{array}$ & $\begin{array}{c}\text { BJH pore } \\
\text { Diameter }(\mathbf{n m})\end{array}$ \\
\hline \hline PS1 & 334 & 0.33 & 5.5 \\
\hline PS2 & 432 & 0.45 & 8.6 \\
\hline PS3 & 459 & 0.75 & 15.0 \\
\hline PS4 & 296 & 0.81 & 18.2 \\
\hline PS5 & 371 & 0.74 & 33.2 \\
\hline
\end{tabular}


hand, the well known $\mathrm{Si}-\mathrm{H}\left(\mathrm{D}_{2} \mathrm{H}, \quad-34.7 \mathrm{ppm}\right)$ peak disappeared by self-hydroxylation and condensation of PMHS in the presence of $\mathrm{NaOH}$ or $\mathrm{K}_{2} \mathrm{HPO}_{4} 3 \mathrm{H}_{2} \mathrm{O}$ in water and ethanol $[5,9,31,32]$. The $\mathrm{M}^{1}, \mathrm{~T}^{2}$ and $\mathrm{T}^{3}$ peaks of $\mathrm{PS} 1$, PS3 and PS5 confirmed the cross linked networks of the siloxane chain. Significant changes in the peak intensity of $\mathrm{T}^{2}$ at $-55.9 \mathrm{ppm}$ were observed after increasing the $\mathrm{NaOH}$ concentration. These changes would not affect the functional groups present in the superhydrophobic powder. A similar spectrum was also observed for the sample prepared from $\mathrm{K}_{2} \mathrm{HPO}_{4} .3 \mathrm{H}_{2} \mathrm{O}$ (PS5). The results suggest that an increase in the $\mathrm{NaOH}$ or $\mathrm{K}_{2} \mathrm{HPO}_{4} 3 \mathrm{H}_{2} \mathrm{O}$ concentration added to $\mathrm{PMHS}$ might alter the surface properties and particle size rather than the functional groups present in the material.

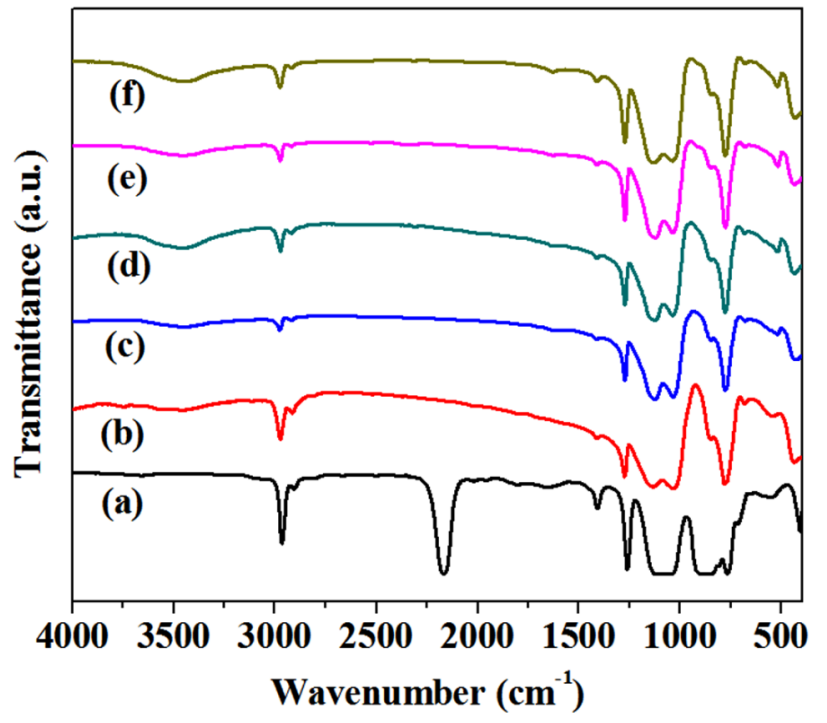

Figure 7: FTIR spectra of the synthesized superhydrophobic powder obtained with various concentrations of $\mathrm{NaOH}$ ((a) PMHS, (b) PS1, (c) PS2, (d) PS3, (e) PS4, and (f) PS5).

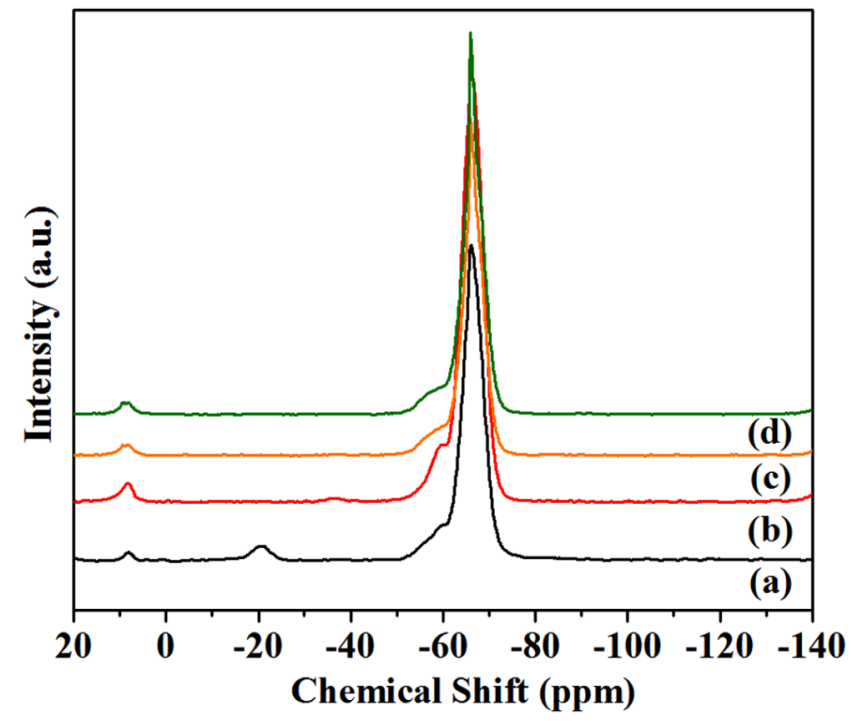

Figure 8: ${ }^{29}$ Si-CP-MAS NMR spectra of the synthesized superhydrophobic powder obtained with various concentrations of $\mathrm{NaOH}((\mathbf{a}) \mathrm{PS} 1,(\mathbf{b}) \mathrm{PS} 3,(\mathbf{c}) \mathrm{PS} 5)$, and $\mathrm{K}_{2} \mathrm{HPO}_{4} \cdot 3 \mathrm{H}_{2} \mathrm{O}$ ((d) PK5).
Figure 9 shows the TGA curves of the PS1-PS5 samples. The strong organic group [MeSiO] present in PMHS might show very good thermal stability over a range of applications. The hydroxylation and polycondensation of PMHS might further enhance the thermal stability of the material due to the presence of methyl functional groups at the cross linked network of the siloxane backbone [9, 33]. PS1 revealed an initial decomposition temperature of $\sim 325{ }^{\circ} \mathrm{C}$ (Figure 9a). This good thermal stability was attributed mainly to the network structure of the superhydrophobic powder. On the other hand, the organic moiety decomposed at a high decomposition temperature. The maximum decomposition of PS1 occurred at $\sim 445^{\circ} \mathrm{C}$ (Figure 9a). The material looses the organic moieties beyond this temperature with complete removal observed at more than $605{ }^{\circ} \mathrm{C}$. At that stage, the superhydrophobic powder became superhydrophilic [5].

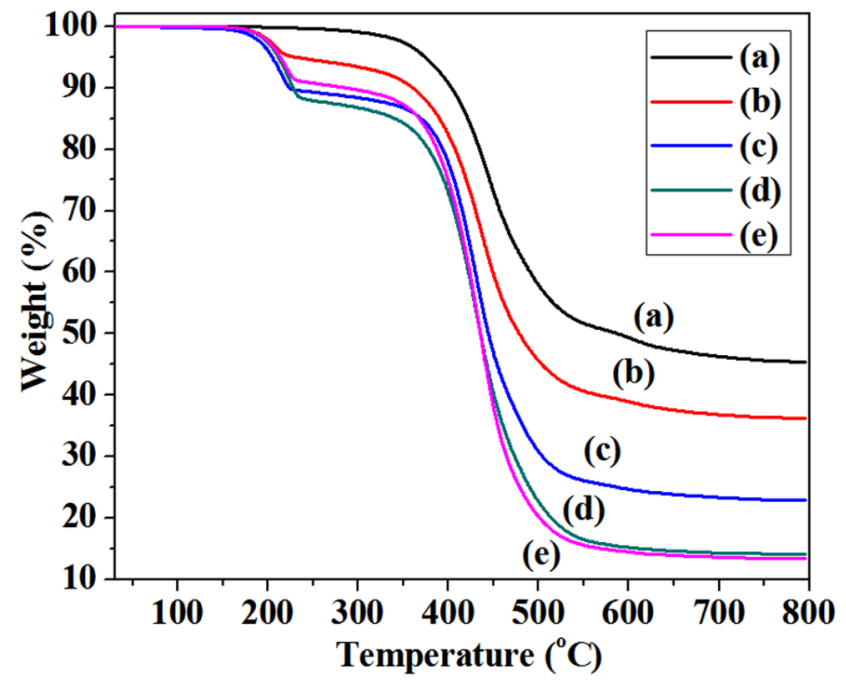

Figure 9: TG Analysis of the synthesized superhydrophobic powder obtained with various concentrations of $\mathrm{NaOH}$ ((a) PS1, (b) PS2, (c) PS3, (d) PS4, and (e) PS5).

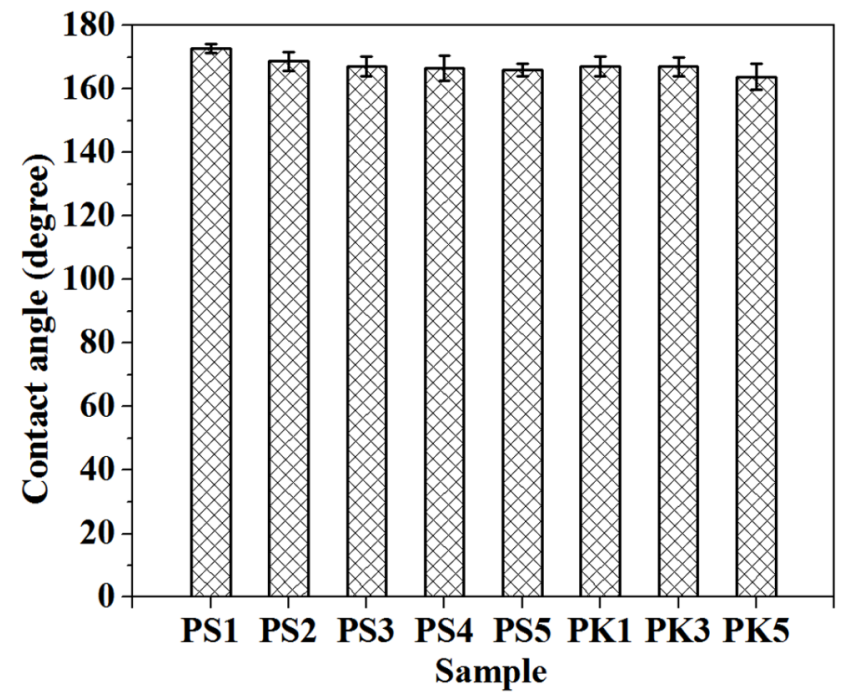

Figure 10: SCA values of the superhydrophobic powder after adding various concentration of $\mathrm{NaOH}$ (PS1, PS2, PS3, PS4, and PS5) or $\mathrm{K}_{2} \mathrm{HPO}_{4} \cdot 3 \mathrm{H}_{2} \mathrm{O}(\mathrm{PK} 1, \mathrm{PK} 3$, and PK5). 


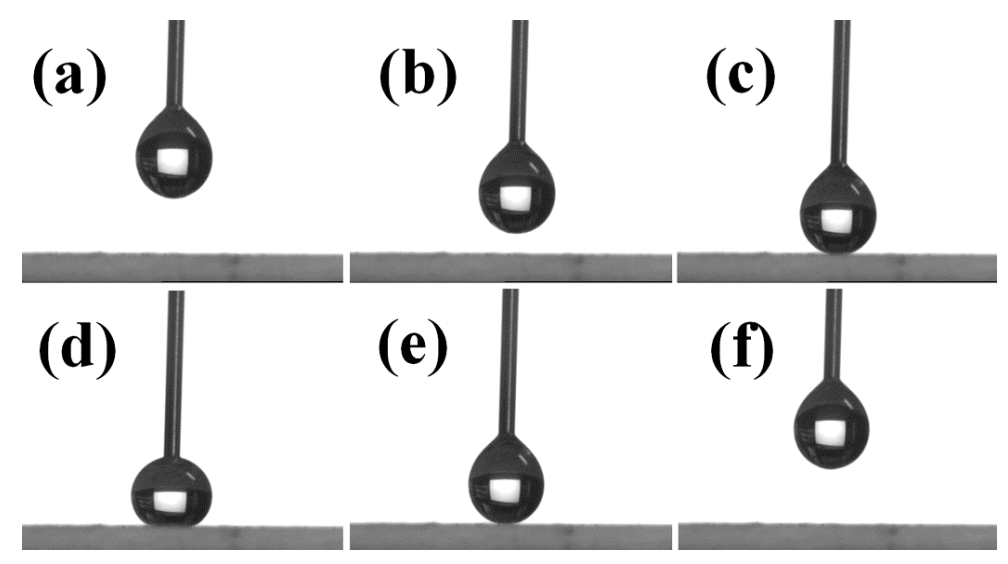

Figure 11: Optical images of a water droplet before and after adhesion and release on the superhydrophobic surface.

The superhydrophobic powder synthesized at other $\mathrm{NaOH}$ concentrations showed partial reduction in the thermal stability of the material (Figure 9b-e). The maximum decomposition occurred at $\sim 435{ }^{\circ} \mathrm{C}$. The decrease in thermal stability by the increase in $\mathrm{NaOH}$ might be related to the gelation of PMHS. The enhanced gelation of PMHS under strong basic medium may hinder the formation of continuous hydrophobic siloxane chains. During this stage, the surface properties of the material were changed significantly and a partial decrease in thermal stability was observed. PMHOS powder showed superhydrophobic properties by placing a water droplet on the surface. The superhydrophobicity was checked further by coating the dispersed (in ethanol) PMHOS on a glass substrate. The coated powder exhibited a superhydrophobic contact angle (CA) of higher than $170^{\circ}$ and non-stick properties (Figure 10), regardless of either the $\mathrm{NaOH}$ concentrations or $\mathrm{K}_{2} \mathrm{HPO}_{4} \cdot 3 \mathrm{H}_{2} \mathrm{O}$ concentrations. Figure 11 clearly shows the non-adhesion properties of the coated substrate.

\section{CONCLUSIONS}

Superhydrophobic PMHOS was synthesized using a one-pot approach with various concentrations of $\mathrm{NaOH}$ (within 2 days) or $\mathrm{K}_{2} \mathrm{HPO}_{4} 3 \mathrm{H}_{2} \mathrm{O}$ (within 4-5 days). Gelation of PMHS did not occur after the addition of aqueous ammonia $(0.1 \mathrm{M}$, $0.3 \mathrm{M}$ and $0.5 \mathrm{M})$ or $\mathrm{HCl}(0.1 \mathrm{M}, 0.3 \mathrm{M}$ and $0.5 \mathrm{M})$ in the presence of ethanol and water. Increasing the concentration of $\mathrm{NaOH}$ leads to a shorter gelation time (from $8 \mathrm{hr}$ to $2 \mathrm{hr}$ ). On the other hand, a significant decrease in the gelation time $(96-120 \mathrm{hr})$ occurred after introducing $\mathrm{K}_{2} \mathrm{HPO}_{4} \cdot 3 \mathrm{H}_{2} \mathrm{O}$. PMHOS maintained a mesoporous (Type IV hysteresis loop) structure at all $\mathrm{NaOH}$ concentrations. The powder showed complete non-adhesive surface properties on a coated glass substrate. The static contact angle (SCA) confirmed the formation of superhydrophobic powder by the use of $\mathrm{NaOH}$ or $\mathrm{K}_{2} \mathrm{HPO}_{4} \cdot 3 \mathrm{H}_{2} \mathrm{O}$. The results showed that the hydrolysis and condensation of the $\mathrm{Si}-\mathrm{H}$ groups in $\mathrm{PMHS}$ are strongly dependent on the concentrations of $\mathrm{NaOH}$ for the rapid synthesis of superhydrophobic powder. On the other hand, increasing the concentration of $\mathrm{NaOH}$ resulted in a significant change in the surface properties and particle size. An optimized superhydrophobic powder was synthesized successfully by using various concentrations of $\mathrm{NaOH}$ and $\mathrm{K}_{2} \mathrm{HPO}_{4} .3 \mathrm{H}_{2} \mathrm{O}$ based on the present experimental procedure. The superhydrophobic powder can be also reproduced rapidly by the removal of solvent immediately after the gelation of the siloxane polymer at $150{ }^{\circ} \mathrm{C}$.

\section{ACKNOWLEDGEMENTS}

This study was supported by the National Research Foundation of Korea (NRF) Grant funded by The Ministry of Science, ICT \& Future Planning, Korea, Pioneer Research Center Program (2010-0019308/2010-0019482) and BK 21 Plus Program (21A2013800002).

\section{REFERENCES}

[1] Onda T, Shibuichi S, Satoh N, Tsujii K. Super-water-repellent fractal surfaces. Langmuir 1996; 12: 2125-7. http://dx.doi.org/10.1021/la9504180

[2] Barthlott W, Neinhuis C. Purity of the sacred lotus or escape from contamination in biological surfaces. Planta 1997; 202: 1-8. http://dx.doi.org/10.1007/s004250050096

[3] Lafuma A, Quéré D. Superhydrophobic states. Nat Mater 2003; 2: 457-60. http://dx.doi.org/10.1038/nmat924

[4] Nagappan S, Park SS, Ha CS. Recent advances in superhydrophobic nanomaterials and nanoscale systems. J Nanosci Nanotechnol 2014; 14: $1441-62$ http://dx.doi.org/10.1166/inn.2014.9194

[5] Nagappan S, Park JJ, Park SS, Lee WK, Ha CS. Bio-inspired, multipurpose and instant superhydrophobic-superoleophilic lotus leaf powder hybrid micro-nanocomposites for selective oil spill capture. $J$ Mater Chem A 2013; 1: 6761-9. http://dx.doi.org/10.1039/c3ta00001j

[6] Tian J, Fu N, Chen XD, Shen W. Respirable liquid marble for the cultivation of microorganisms. Colloids Surf B: Biointerfaces 2013; 106: $187-90$.

http://dx.doi.org/10.1016/j.colsurfb.2013.01.016

[7] Wu T, Chen M, Zhang L, et al. Three-dimensional graphene-based aerogels prepared by a self-assembly process and its excellent catalytic and absorbing performance. J Mater Chem A 2013; 1: 761221.

http://dx.doi.org/10.1039/c3ta10989e

[8] Pang $\mathrm{CH}$, Lee GY, Kim TI, et al. A flexible and highly sensitive straingauge sensor using reversible interlocking of nanofibers. Nat Mater 2012; 11: 795-801. http://dx.doi.org/10.1038/nmat3380

[9] Yang DJ, Li JP, Xu Y, et al. Direct formation of hydrophobic silicabased micro/mesoporous hybrids from polymethylhydrosiloxane and tetraethoxysilane. Microporous Mesoporous Mater 2006; 95: 180-6. http://dx.doi.org/10.1016/j.micromeso.2006.05.022 
[10] Mozumder MS, Zhang H, Zhu J. Mimicking lotus leaf: Development of micro-nanostructured biomimetic superhydrophobic polymeric surfaces by ultrafine powder coating technology. Macromol Mater Eng 2011: 296: 929-36. http://dx.doi.org/10.1002/mame.201100080

[11] Zhao $\mathrm{Y}$, Fang J, Wang $\mathrm{H}$, Wang $\mathrm{X}$, Lin T. Magnetic liquid marbles: Manipulation of liquid droplets using highly hydrophobic $\mathrm{Fe}_{3} \mathrm{O}_{4}$ nanoparticles. Adv Mater 2009; 21: 1-4.

[12] Song $W$, Oliveira $M B$, Sher $P$, Gil $S$, Nóbrega JM, Mano JF. Bioinspired methodology for preparing magnetic responsive chitosan beads to be integrated in a tubular bioreactor for biomedical applications. Biomed Mater 2013; 8: 045008 (1-8).

[13] Li XM, Reinhoudt D, Crego-Calama M. What do we need for a superhydrophobic surface? A review on the recent progress in the preparation of superhydrophobic surfaces. Chem Soc Rev 2007; 36: 1350-68.

http://dx.doi.org/10.1039/b602486f

[14] Qu HQ, Hao JW, Wu WH, Zhao XW, Jia S. Optimization of sol-gel coatings on the surface of ammonium polyphosphate and its application in epoxy resin. J Fire Sci 2012; 30: 357-71. http://dx.doi.org/10.1177/0734904112442360

[15] Nagappan S, Sung AR, Ha CS. Preparation of stable hydrophobic bio-based silica hybrid micro-nanocomposites. J Biobased Mater Bioenergy 2014; 8: 175-83.

http://dx.doi.org/10.1166/ibmb.2014.1421

[16] Laine RM, Rahn JA, Youngdahl KA, et al. Synthesis and hightemperature chemistry of methylsilsesquioxane polymers produced by titanium-catalyzed redistribution of methylhydridooligo-andpolysiloxanes. Chem Mater 1990; 2: 464-72. http://dx.doi.org/10.1021/cm00010a028

[17] Han SH, Lee JY, Koo SM. Synthesis and characterization of polymethylsilsesquioxane-based hybrid polymers. J Ind Eng Chem 2004; 10: 813-20.

[18] Huang YW, Liu WQ. Sol-gel composite coatings from methyltriethoxysilane and polymethylhydrosiloxane. J Sol-Gel Sci Technol 2010; 55: 261-8.

http://dx.doi.org/10.1007/s10971-010-2243-4

[19] Lawrence NJ, Drew MD, Bushell SM. Polymethylhydrosiloxane: A versatile reducing agent for organic Synthesis. J Chem Soc Perkin Trans 1999; 1: 3381-91. http://dx.doi.org/10.1039/a903662h

[20] Nagappan S, Choi MC, Sung G, et al. Highly transparent, hydrophobic fluorinated polymethylsiloxane/silica organic-inorganic hybrids for anti-stain coating. Macromol Res 2013; 21: 669-80. http://dx.doi.org/10.1007/s13233-013-1069-7

[21] Nagappan S, Park JJ, Park SS, et al. Polymethylhydrosiloxane-based organic-inorganic hybrids for amphiphobic coatings. Compos Interfaces 2013; 20: 33-43

http://dx.doi.org/10.1080/15685543.2013.762892

[22] Zhang B, Guo S, Shao B. Synthesis and characterization of liquid crystalline ionomers with polymethylhydrosiloxane main-chain- and side-chain-containing sulfonic acid groups. J Appl Polym Sci 1998; 68: 1555-61.

http://dx.doi.org/10.1002/(SICI)10974628(19980606)68:10<1555::AID-APP2 $>3.0$. CO;2-G
[23] Chauhan BPS, Sardar R. Self-assembled stable silver nanoclusters and nanonecklace formation: Poly(methylhydrosiloxane)-mediated one-pot route to organosols. Macromolecules 2004; 37: 5136-9. http://dx.doi.org/10.1021/ma0496798

[24] Zhang Y, Chen HL, Wen Y, Yuan YB, Wu W, Liu C. Tunable wettability of monodisperse core-shell nano-SiO2modifiedwith poly(methylhydrosiloxane) and allyl-poly(ethylene glycol). Colloids Surf A: Physicochem. Eng. Aspects 2014; 441: 16- 24. http://dx.doi.org/10.1016/i.colsurfa.2013.08.079

[25] Yang DJ, Xu Y, Wu D, Sun YH, Zhu HY, Deng F. Superhydrophobic mesoporous silica with anchored methyl groups on the surface by a one-step synthesis without surfactant template. J Phys Chem C 2007; 111: 999-1004. http://dx.doi.org/10.1021/ip065815u

[26] Zhai SR, Song Y, Zhai B, An QD, Ha CS. One-pot synthesis of hybrid mesoporous xerogels starting with linear polymethylhydrosiloxane and bridged bis-(trimethoxysilyl)ethane. Microporous Mesoporous Mater 2012; 163: 178-85. http://dx.doi.org/10.1016/i.micromeso.2012.07.022

[27] Brunauer S, Emmett PH, Teller E. Adsorption of gases in multimolecular layers. J Am Chem Soc 1938; 60: 309-19.

http://dx.doi.org/10.1021/ja01269a023

[28] Nagappan S, Park SS, Yu EJ, et al. A highly transparent, amphiphobic, stable and multi-purpose poly(vinyl chloride) metallopolymer for anti-fouling and anti-staining coatings. J Mater Chem A 2013; 1: 12144-53.

http://dx.doi.org/10.1039/c3ta11887h

[29] Uchida N, Ishiyama N, Kato Z, Uematsu K. Chemical effects of DCCA to the sol-gel reaction process. J Mater Sci 1994; 29: 5188-92. http://dx.doi.org/10.1007/BF01151115

[30] Gardner KL, McNally G. The gel effect and its relationship to particle size distribution on the suspension polymerization of styrenedivinylbenzene systems. J Polym Sci: Polym Lett Edi 1978; 16: 267 70. http://dx.doi.org/10.1002/pol.1978.130160603

[31] Hetem M, Rutten G, Vermeer B, et al. Deactivation with polymethylhydrosiloxane: A comparative study with capillary gas chromatography and solid-state ${ }^{29} \mathrm{Si}$ nuclear magnetic resonance spectroscopy. J. Chromatogr A 1989; 477: 3-24. http://dx.doi.org/10.1016/S0021-9673(01)89614-X

[32] Huang YW, Liu WQ. Sol-gel composite coatings from methyltriethoxysilane and polymethylhydrosiloxane. J Sol-Gel Sci Technol 2010; 55: 261-68. http://dx.doi.org/10.1007/s10971-010-2243-4

[33] Yang D, Xu Y, Xu W, Wu D, Sun Y, Zhu H. Tuning pore size and hydrophobicity of macroporous hybrid silica films with high optical transmittance by a non-template route. J Mater Chem 2008; 18: 555762. http://dx.doi.org/10.1039/b804967j

(C) 2014 Nagappan and Ha; Licensee Lifescience Global.

This is an open access article licensed under the terms of the Creative Commons Attribution Non-Commercial License (http://creativecommons.org/licenses/by-nc/3.0/) which permits unrestricted, non-commercial use, distribution and reproduction in any medium, provided the work is properly cited. 